\title{
Dimensional Accuracy in Dry Micro Wire Electrical Discharge Machining
}

\section{Mohammad Yeakub Ali, Asfana Banu, Muhammad Salehan, Erry Y. T. Adesta*, Muataz Hazza, and Muhammad Shaffiq}

\author{
Department of Manufacturing and Materials Engineering \\ International Islamic University Malaysia \\ PO Box 10, 50728 Kuala Lumpur, Malaysia \\ *Email: eadesta@iium.edu.my
}

\begin{abstract}
Dimensional accuracy is important in fabricating miniaturized product in order to reduce the material waste and machining cost as well as to achieve a better quality product. This paper presents the analysis and modelling of dimensional accuracy in dry micro wire electrical discharge machining with control parameters of gap voltage and wire tension. The investigation was performed on stainless steel using integrated multi-process micro machine tools DT 110 with compressed air as the dielectric fluid and tungsten as the wire electrode. The dimensional accuracy was determined through kerf width differences of the machined slots. The kerf width was measured using scanning electron microscope. Full factorial was used to design the experiment while analysis of variance (ANOVA) was used to analyse the results as well as to evaluate the adequacy of the developed model. Based on ANOVA, both parameters; gap voltage and wire tension have high influence on kerf width differences. The optimum machining parameters for minimum kerf width differences were found to be $85 \mathrm{~V}$ gap voltage and $10 \%$ wire tension. The developed model is adequate since the percentage error $(2.13 \%)$ is relatively small. It is recommended that different type of gases should be used for further investigation in order to determine the accuracy of the dry micro wire EDM.
\end{abstract}

Keywords: Dry wire EDM, Dry micro wire EDM, Dimensional accuracy, Kerf

\section{INTRODUCTION}

The demand in fabricating complex micro parts with high accuracy using electrical discharge machining (EDM) is increasing especially in biomedical, electronics, and aerospace industry [1-4]. EDM is preferable due to a non-contact machining operation where electrical energy is used to produce a series of discrete sparks between the tool electrode and the workpiece [5-8]. EDM offers a precise solution compared to the other traditional machining method, since it can eliminate mechanical stresses, chatter, and vibration during machining [5-6]. The machining operation is performed in the presence of liquid dielectric; normally mineral oilbased liquid or hydrocarbon liquids. The dielectrics act as a deionizing medium for the electrodes for sparks generation and flushes away the debris from the machining gap [5-6], [9-10]. However, these dielectric fluids have certain drawbacks where it can cause fire hazard, generate toxic and non-recyclable dielectric waste, generate toxic fumes, and pose a health hazard to the operators [11-13]. Therefore, green manufacturing method is introduced through EDM process where it is known as the dry EDM.

Dry EDM is a method where gas is used as the dielectric fluid instead of the liquid dielectric, which is supplied through a pipe electrode [14-15]. This dry technique is also applicable for micro fabrication applications for micro level machining process such as dry 
wire EDM, micro dry EDM, and micro dry wire EDM [15-17]. Dry wire EDM also known as the wire EDM using dry dielectric fluid is a modification of the oil wire EDM operation where gas is used as dielectric fluid instead of liquid with wire electrode. The high-pressure gas helps to eliminate the debris and avoids excessive heating between the wire and the workpiece at the machining gap [18-22]. However, this machining method has several shortcomings such as low MRR, poor sharp cutting edge, and high debris deposition $[12,18]$. Even though this type of machining operation has some shortcomings, but it also has some advantages; lower tool wear, better surface quality, lower residual stresses, thinner white layer, and higher accuracy [22]. Micro dry wire EDM has the ability to produce finishing cut with high accuracy since the gap distance between the wire and workpiece is narrow and the process reaction force during the machining operation is negligible compared to the conventional wire EDM [23]. Hence, some researchers suggested that dry wire EDM can be utilised for finish cut with high surface quality especially in manufacturing high precision dies and mold. This is because craters with smaller volumes are generated due to low energy intensity of the gases [24].

Dimensional accuracy of the machined features, which can be affected by kerf width differences (Eq. 1), is one of the critical issues in wire EDM and micro wire EDM operation [24-25]. Kerf is a width of the machined slots also refers to the amount of the material that is removed during the machining [26]. Kerf and the sparking gap are interrelated to each other in determining the dimensional accuracy of the finishing parts [22]. Compared to the conventional wire EDM, the kerf variations have higher influences on dimensional accuracy in micro wire EDM. This is due to the relative error found in miniature parts produced by the micro wire EDM are bigger than the corresponding values in conventional wire EDM [6, 27]. The kerf variation are usually caused by the wire tool deflection and wire vibrations in the discharge gap are the factors that affect the wire EDM machining accuracy [27]. When higher wire tension is used, lower kerf can be achieved resulted in better accuracy since the wire vibration is less. Nevertheless, wire breakage tends to occur if the wire tension is too high [28-29].

It was found that dry micro wire EDM has a high potential in manufacturing miniaturized product with high accuracy and precision. However, a comprehensive study on dry micro wire EDM is still too little to be implemented for the industrial application [26]. Therefore, the objective of this study is to investigate the effect of the process parameters; gap voltage and wire tension; on dimensional accuracy in dry micro wire EDM on stainless steel using compressed air as dry dielectric fluid and tungsten as wire electrode.

\section{METHODOLOGY}

The experiments were design using full factorial of two factors with four levels $\left(2^{4}\right)$ where the controlled parameters were the gap voltage and the wire tension. The design was replicated twice $\left(2^{4} \times 2\right)$, which concluded into 32 experiments [30]. The replication of the factorial is necessary since it provides information on the error variance and increases the precision for each estimated coefficient [31]. The experiments were conducted on a stainless steel $(13 \mathrm{~mm} \times 30 \mathrm{~mm} \times 0.25 \mathrm{~mm})$ using micro wire EDM with multi-process micro machine tools, DT-110 (Mikrotools Inc., Singapore) as shown in Figure 1a. Stainless steel is one of the commonly used materials in fabricating miniaturized parts especially micropillars for cooling purposes in electronic components [32-34]. Tungsten wire with $70 \mu \mathrm{m}$ was used as the tool electrode since it has high tensile strength and load-carrying capability [35]. Compressed air [36] was used as the dielectric fluid. The experimental parameters are listed in Table 1 were selected based on the capability of the machine, type of machining material, and tool material [3]. 
After machining, the workpiece was cleaned in ethanol for 5 min using an ultrasonic cleaning machine. In order to get the dimensional accuracy, the differences between the kerf width is necessary as shown in Eq. 1. The measurement of the kerf width was determined using the scanning electron microscope (SEM). SEM is a basic type of electron microscope, where it is capable in producing high-resolution $(5 \mathrm{~nm})$ three dimensional images in order to study the microstructure morphology of a specimen [37]. The measurement was taken at six different places as shown in Figure 1b. This is because in order to calculate the differences of the kerf width (Eq. 1), average of three measurements were taken at the beginning of the machined slot while average for the other three measurements were taken at the end of the machined slot. Average of the kerf width at the beginning of the machined slot, D, average of the kerf width at the end of the machined slot, $d$, and kerf width differences are tabulated in Table 2. Analysis of variance (ANOVA) approach was used to analyse the results and the adequacy of the developed model is confirmed through the statistical features associated with it $[31,38]$.

$$
\text { Kerf width differences }=D-d
$$

where, $D=$ average of the kerf width at the beginning of the machined slot, $d=$ average of the kerf width at the end of the machined slot.

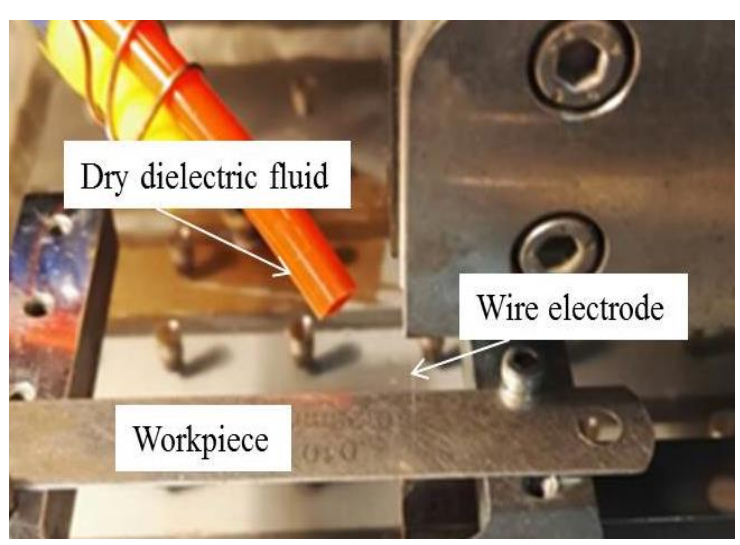

(a)

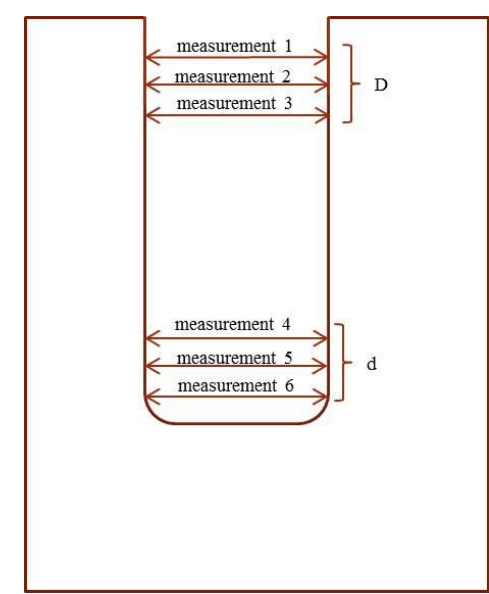

(b)

Figure 1: (a) Experimental setup and (b) kerf width measurements

Table 1. Experimental parameters

\begin{tabular}{llllll}
\hline \multirow{2}{*}{ Control Parameters } & \multicolumn{5}{c}{ Level } \\
\cline { 2 - 6 } & Factors & I & II & III & IV \\
\hline Gap voltage $(\mathrm{V})$ & $\mathrm{v}$ & 85 & 95 & 105 & 115 \\
Wire tension $(\%)$ & $\mathrm{t}$ & 10 & 13 & 16 & 18 \\
\hline Fixed Parameters: & \multicolumn{5}{c}{ Stainless steel S304 } \\
\hline Workpiece material & Tungsten wire $(\varnothing 70 \mu \mathrm{m})$ & \\
Tool electrode & Compressed air & & \\
Dielectric fluid & 0.0345 & & & \\
Dielectric pressure $(\mathrm{MPa})$ & 0.4 & & & \\
Capacitance $(\mu \mathrm{F})$ & 24 & & & \\
Threshold $(\%)$ & 0.5 & 0.4 & & & \\
Wire speed $(\mathrm{rpm})$ & & & & & \\
Wire feed $(\mu \mathrm{m} / \mathrm{s})$ & & &
\end{tabular}


Table 2. Experimental results for average kerf width and average kerf width differences

\begin{tabular}{|c|c|c|c|c|c|c|c|c|}
\hline \multirow{4}{*}{ Exp } & \multicolumn{2}{|c|}{ Parameters } & \multicolumn{6}{|c|}{ Response } \\
\hline & \multirow{3}{*}{$\begin{array}{c}\text { Gap } \\
\text { voltage } \\
(\text { V) }\end{array}$} & \multirow{3}{*}{$\begin{array}{c}\text { Wire } \\
\text { tension } \\
(\%)\end{array}$} & \multicolumn{6}{|c|}{ Average of kerf width $(\mu \mathrm{m})$} \\
\hline & & & \multicolumn{3}{|c|}{ Replication 1} & \multicolumn{3}{|c|}{ Replication 2} \\
\hline & & & D & d & $\begin{array}{c}\text { Differences } \\
(\mathrm{D}-\mathrm{d})\end{array}$ & D & d & $\begin{array}{c}\text { Differences } \\
(\mathrm{D}-\mathrm{d})\end{array}$ \\
\hline 1 & 85 & 10 & 98.00 & 96.00 & 2.00 & 96.80 & 95.20 & 1.60 \\
\hline 2 & 95 & 10 & 97.00 & 103.50 & 6.50 & 98.80 & 93.20 & 5.60 \\
\hline 3 & 105 & 10 & 104.00 & 97.50 & 6.50 & 102.00 & 93.60 & 8.40 \\
\hline 4 & 115 & 10 & 84.00 & 83.00 & 1.00 & 102.00 & 99.20 & 2.80 \\
\hline 5 & 85 & 13 & 99.00 & 95.50 & 3.50 & 98.00 & 96.40 & 1.60 \\
\hline 6 & 95 & 13 & 96.50 & 92.50 & 4.00 & 96.00 & 92.00 & 4.00 \\
\hline 7 & 105 & 13 & 103.50 & 95.00 & 8.50 & 96.00 & 93.20 & 2.80 \\
\hline 8 & 115 & 13 & 95.50 & 88.50 & 7.00 & 99.60 & 92.00 & 7.60 \\
\hline 9 & 85 & 16 & 97.00 & 95.00 & 2.00 & 95.60 & 92.40 & 3.20 \\
\hline 10 & 95 & 16 & 98.00 & 96.50 & 1.50 & 96.00 & 94.80 & 1.20 \\
\hline 11 & 105 & 16 & 102.00 & 100.00 & 2.00 & 93.20 & 89.60 & 3.60 \\
\hline 12 & 115 & 16 & 100.50 & 95.50 & 5.00 & 92.60 & 86.00 & 6.60 \\
\hline 13 & 85 & 18 & 103.50 & 96.00 & 7.50 & 93.60 & 85.60 & 8.00 \\
\hline 14 & 95 & 18 & 97.50 & 93.50 & 4.00 & 89.20 & 86.40 & 2.80 \\
\hline 15 & 105 & 18 & 98.50 & 94.00 & 4.50 & 91.20 & 88.40 & 2.80 \\
\hline 16 & 115 & 18 & 91.00 & 90.50 & 0.50 & 90.80 & 88.40 & 2.40 \\
\hline
\end{tabular}

Table 3. ANOVA for kerf width differences

\begin{tabular}{cccccc}
\hline \multicolumn{1}{c}{ Source } & Sum of squares & DF & Mean Square & F value & Prob > F \\
\hline Model & 155.75 & 9 & 17.31 & 13.23 & $<0.0001$ \\
$v$ - Gap voltage & 33.74 & 1 & 33.74 & 25.80 & $<0.0001$ \\
$t$ - Wire tension & 40.41 & 1 & 40.41 & 30.89 & $<0.0001$ \\
$v^{2}$ & 5.51 & 1 & 5.51 & 4.21 & 0.0522 \\
$t^{2}$ & 0.77 & 1 & 0.77 & 0.59 & 0.4508 \\
$v t$ & 19.15 & 1 & 19.15 & 14.64 & 0.0009 \\
$v^{3}$ & 8.15 & 1 & 8.15 & 6.23 & 0.0206 \\
$t^{3}$ & 14.93 & 1 & 14.93 & 11.41 & 0.0027 \\
$v^{2} t$ & 47.70 & 1 & 47.70 & 36.47 & $<0.0001$ \\
$v t^{2}$ & 56.17 & 1 & 56.17 & 42.94 & $<0.0001$ \\
\hline Residual & 28.78 & 22 & 1.31 & & \\
Lack of Fit & 13.46 & 6 & 2.24 & 2.34 & 0.0812 \\
Pure Error & 15.32 & 16 & 0.96 & & \\
Corrected Total & 184.53 & 31 & & & \\
\hline Standard deviation & \multicolumn{7}{c}{} & 1.14 & $\mathrm{R}^{2}$ & & 0.8440 \\
Mean & & 4.21 & Adjusted $\mathrm{R}^{2}$ & & 0.7802 \\
Coefficient of variation & & 27.17 & Predicted $\mathrm{R}^{2}$ & & 0.6625 \\
Predicted residual error of sum of square & 62.28 & Adequate precision & 10.029 \\
\hline
\end{tabular}

\section{RESULTS AND DISCUSSION}

ANOVA was used to check the adequacy of the developed statistical model. Equation (2) was developed based on the response surface cubic model. Based on Table 3, the model Fvalue of 13.23 implies that the model is significant. The value of Prob > F less than $5 \%$ indicates the factors $v$ (gap voltage), $t$ (wire tension), $v t$ (gap voltage and wire tension), $v^{3}$ (gap voltage), $t^{3}$ (wire tension), $v^{2} t$ (gap voltage and wire tension), $v t^{2}$ (gap voltage and wire 
tension) are significant [38-39]. The Prob > F value of 0.0812 for the lack-of-fit indicates that the term is insignificant since the value is larger than 0.05 . The insignificant lack-of-fit is desirable because it shows that the model is fitted adequately into the data [30, 38]. Besides that, the variability amount of the mean of the data is presented by $\mathrm{R}^{2}$, which is around 0.84 . As for the Predicted $R^{2}$, the value is in reasonable agreement with Adjusted $R^{2}$ since the difference is within $0.12[3,38]$.

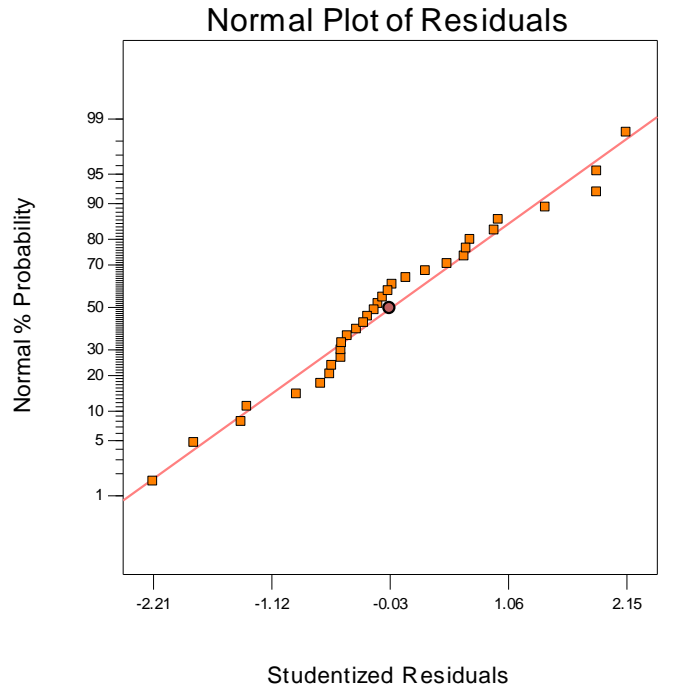

(a)

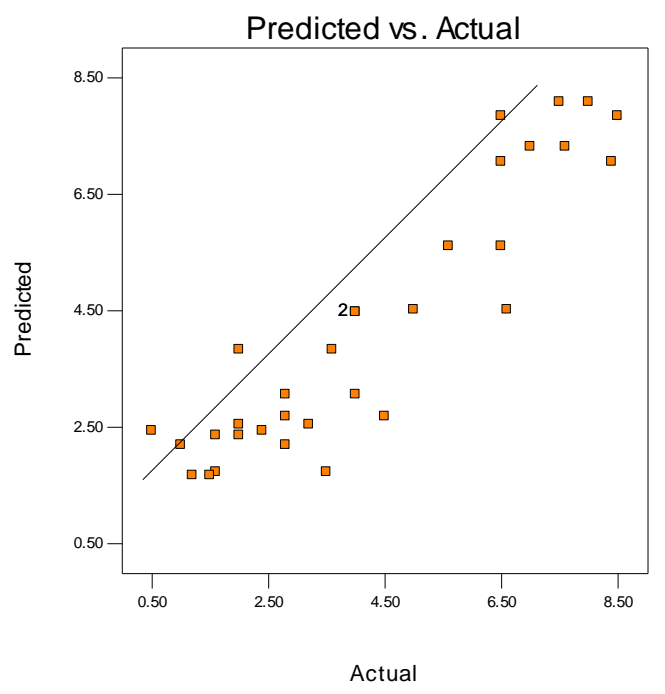

(c)

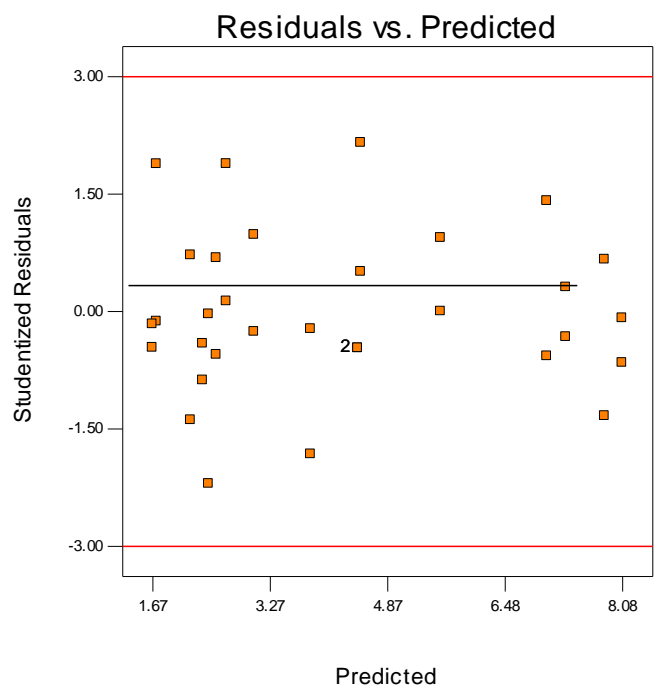

(b)

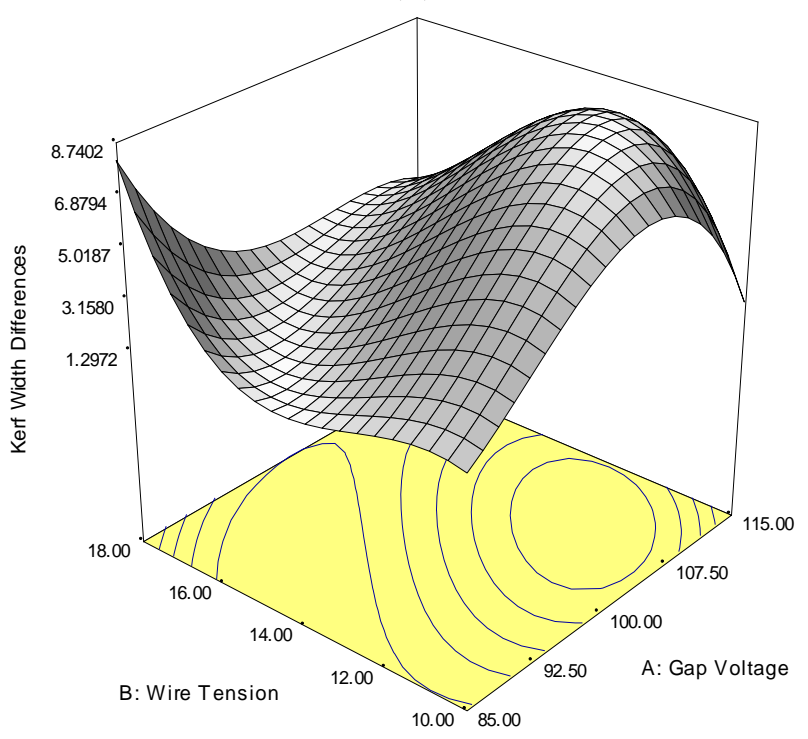

(d)

Figure 2. Diagnostic test based on (a) normal probability of residuals plot, (b) residuals vs. predicted plot; (c) Model prediction based on predicted vs. actual plot; and (d) Three dimensional plot of kerf width differences with gap voltage and wire tension.

In this case, the signal-to-noise ratio that is expressed through the Adequate precision, 10.029 shows that the signal is tolerable. Hence, through these statistical characteristics, the model seems adequate to predict the behaviour of the dimensional accuracy that is determined by the kerf width differences $[3,38]$. 


$$
-7.52 \times 10^{-4} v^{3}+0.05 t^{3}+4.03 \times 10^{-3} v^{2} t-0.02 v t^{2}
$$

where, $v=$ gap voltage $(\mathrm{V})$ and $t=$ wire tension $(\%)$.

Figure $2 \mathrm{a}$ and $2 \mathrm{~b}$ shows the diagnostic test through the normal probability of residual plot and residual versus predicted plot respectively. The residual of the data determines the adequacy of the model when it is normally distributed, unstructured, and with constant variance [38]. Based on Figure 2a, the normality condition is satisfied since the residuals of the data approximately followed the straight-line pattern. As for the residual versus predicted plot (Figure 2b), the plot is considered adequate since the values are scattered randomly which shows that the variances of the original observations are constant for all values [38]. From the Figure 2, it is observed that the data are distributed around the straight line that implies the predicted kerf width differences are within the experimental region [38]. Hence, based on these three figures, it is confirmed that the developed model is adequate. The model also has the capability to predict the pattern of the kerf width differences that may lead to a better level of dimensional accuracy [38].

Figure $2 \mathrm{~d}$ shows the three dimensional plot of kerf width differences with gap voltage and wire tension. Based on the figure, when the wire tension is low the kerf width difference is at the peak (high). This is because the wire vibration is expected to reduce with the increment of wire tension that lead to the reduction of kerf width differences [3, 29]. Besides that, the kerf width difference is at the highest when the gap voltage increases resulted in low dimensional accuracy of the machined slot. This situation occurs due to the wire vibration [40-41]. This is because, during the machining operation, there are several forces acting on the wire that lead to low dimensional accuracy [40-41]. The forces are reaction forces from the pressure of the gas bubbles during the erosion mechanism, hydrodynamic forces because of the flushing system, the electrostatic forces that act on the wire, and the electromagnetic forces from the spark generation [24, 40, 42]. Besides that, the increment of the wire vibration may also happen when high discharge energy is used. In this case, one of the factors that affect the discharge energy is gap voltage [24-25, 40]. However, wire vibration in dry wire EDM considered as minimum compared to the conventional wire EDM. This is because in dry wire EDM the process reaction force is negligible and the gap distance is narrower [22]. Based on the Paschen's law, the breakdown of gas discharges are affected by the pressure and the gap distance between the tool electrode and the workpiece. The electrical discharge is produced due to high electric fields generated in the small gap distance [43]. Since the energy and the plasma pressure generated in gases are low [26], the wire vibration is also low which leads to better dimensional accuracy.

\section{Optimization and Verification}

The ANOVA-based optimization was carried out in order to get optimum values of the parameters for minimum kerf width differences. The minimum kerf width difference was $2.35 \mu \mathrm{m}$ with $85 \mathrm{~V}$ gap voltage and $10 \%$ wire tension. The model was verified by conducting experiment based on the optimized parameters. Based on the experiment, the actual kerf width difference $(2.40 \mu \mathrm{m})$ is higher compare to the optimized kerf width difference with maximum error of $2.13 \%$. The percentage error of minimum kerf width differences is relatively small which shows that the developed model is satisfactory.

\section{CONCLUSIONS}

The dry micro wire EDM was performed successfully in this study, and open up opportunities in machining high accuracy miniaturized features. ANOVA was used to analyse the influences of the two parameters, gap voltage and wire tension on kerf width differences. 
The kerf width differences determine the dimensional accuracy of the machined slots. The following conclusions are drawn from the experimental investigation:

1. The model is adequate to predict the behaviour of the dimensional accuracy.

2. Both parameters; gap voltage and wire tension have strong influence on dimensional accuracy. This is because these parameters affect the wire vibration during the machining operation that determines the accuracy of the machined slot.

3. The model predicts minimum kerf width differences $(2.35 \mu \mathrm{m})$ when $85 \mathrm{~V}$ gap voltage and $10 \%$ wire tension are used. The predicted value and experimental kerf width differences value is within $2.13 \%$ error. The developed model is satisfying since the percentage error is relatively small.

4. The investigation for dimensional accuracy for dry micro wire EDM was not found in the recent literature so it cannot be benchmarked. However, this investigation has been done to ascertain the possibility of dimensional accuracy less than $10 \mu \mathrm{m}$ level.

5. It is recommended that detail investigation related to the accuracy of the dry micro wire EDM should be performed using different type of gases since according to the Paschen's law, the breakdown of gas discharges are different based on the type of gases used.

\section{ACKNOWLEDGMENTS}

This research was funded by MOSTI, under Research Grant SF15-016-0066. The authors are thankful to faculty and staff at Micromanufacturing Laboratory at IIUM for their support.

\section{REFERENCES}

[1] Hoang KT, Yang SH. A study on the effect of different vibration-assisted methods in micro-WEDM. Journal of Materials Processing Technology. 2013;213:1616-1622.

[2] Hoang KT, Yang SH. A new approach for micro-WEDM control based on real-time estimation of material removal rate. International Journal of Precision Engineering and Manufacturing. 2015;16:2-241-246.

[3] Banu A, Bakar MA, Ali MY, Adesta EYT. Analysis of WEDM process parameters on surface roughness and kerf using Taguchi method. International Journal of Engineering Materials and Manufacture. 2017;2:4-103-109.

[4] Khan MAR, Rahman MM, Kadirgama K, Maleque MA, Ishak M. Prediction of surface roughness of Ti-6Al-4V in electrical discharge machining: a regression model. Journal of Mechanical Engineering and Sciences. 2011;1:16-24.

[5] Abbas MN, Solomon DG, Fuad Bahari M. A review on current research trends in electrical discharge machining (EDM). International Journal of Machine Tools and Manufacture. 2007;47:7-1214-1228.

[6] Banu A, Ali MY. Electrical discharge machining (EDM): a review. International Journal of Engineering Materials and Manufacturing. 2016;1:1-3-10.

[7] Singh R, Singh B. Comparison of cryo treatment effect on machining characteristics of titanium electric discharge machining. International Journal of Automotive and Mechanical Engineering. 2011;3:239-248.

[8] Mohanty S, Routara BC. A review on machining of metal matrix composites using nanoparticle mixed dielectric in electro-discharge machining. International Journal of Automotive and Mechanical Engineering. 2016;13:2-3518-3539.

[9] Liu Q, Zhang Q, Zhang M, Zhang J. Review of size effects in micro electrical discharge machining. Precision Engineering. 2016;44:29-40. 
[10] Hourmand M, Sarhan AAD, Yusof, NM. Development of new fabrication and measurement techniques of micro-electrodes with high aspect ratio for micro EDM using typical EDM machine. Measurement. 2017;97:64-78.

[11] Azhiri RB, Teimouri R, Baboly MG, Laseman Z. Application of Taguchi, ANFIS and grey relational analysis for studying, modelling and optimization of wire EDM process while using gaseous media. International Journal of Advanced Manufacturing Technology. 2014;71:1-279-295.

[12] Pradeep GM, Dani MSH. A review on the use of pollution free dielectric fluids in wire electrical discharge machining process. Journal of Chemical and Pharmaceutical Sciences. 2015;7:312-315.

[13] Dhakar K, Dvivedi A. Parametric evaluation on near-dry electric discharge machining. Materials and Manufacturing Processes. 2016;31:413-421.

[14] Khatri BC, Rathod P, Valaki JB. Ultrasonic vibration-assisted electric discharge machining: a research review. Proceedings of the Institution of Mechanical Engineers, Part B: Journal of Engineering Manufacture. 2016;1-12.

[15] Wang T, Xie SQ, Xu XC, Chen Q, Lu XC, Zhou SH. Application of uniform design in experiments of WEDM in gas. Advanced Materials Research. 2012;426:11-14.

[16] Skrabalak G, Kozak J. Study on dry electrical discharge machining. Wear. 2010;5:7.

[17] Yu ZB, Takahashi J, Nakajima N, Sano S, Kunieda M. Feasibility of 3-D surface machining by dry EDM. International Journal of Electrical Machining. 2005;10:15-20.

[18] Wang T, Kunieda M. Dry WEDM for finish cut. Key Engineering Materials. 2004;259-260:562-566.

[19] Kunieda M, Lauwers B, Rajurkar KP, Schumacher BM. Advancing EDM through fundamental insight into the process. CIRP Annals-Manufacturing Technology. 2005;54:2-64-87.

[20] Liqing L, Yingjie S. Study of dry EDM with oxygen-mixed and cryogenic cooling approaches. Procedia CIRP. 2013;6:344-350.

[21] Singh P, Chaudhary AK, Singh T, Rana AK. Comparison of outputs for dry EDM and EDM with oil: a review. International Journal for Research in Emerging Science and Technology. 2015;2:6-45-49.

[22] Ghodsiyeh D, Moradi M. Wire Electrical Discharge Machining. In Electrical Discharge Machining (EDM) Types, Technologies and Applications. Jahan MP, Ed. New York: Nova Science Publishers, Inc., 2015;33-65.

[23] Yu Z, Jun T, Masanori K. Dry electrical discharge machining of cemented carbide. Journal of Materials Processing Technology. 2004;149:1-353-357.

[24] Ho KH, Newman ST, Rahimifard S, Allen RD. State of the art in wire electrical discharge machining (WEDM). International Journal of Machine Tools and Manufacture. 2004;44:1247-1259.

[25] Mandal A, Dixit AR. State of art in wire electrical discharge machining process and performance. International Journal of Machining and Machinability of Materials. 2014;16:1.

[26] Hoang KT, Yang SH. Kerf analysis and control in dry micro-wire electrical discharge machining. International Journal of Advanced Manufacturing Technology. 2015;78:1803-1812.

[27] Di S, Chu X, Wei D, Wang Z, Chi G, Liu Y. Analysis of kerf width in micro-WEDM. International Journal of Machine Tools and Manufacture. 2009;49:10-788-792.

[28] Islam MN, Rafai NH, Subramanian SS. Dimensional accuracy achievable in wire-cut electrical discharge machining. In Electrical Engineering and Applied Computing, Lecture Notes in Electrical Engineering. Dordrecht: Springer, 2011;90. 
[29] Balan ASS, Giridharan A. A progress review in wire electrical discharge machining process. International Journal of Automotive and Mechanical Engineering. 2017;14:24097-4124.

[30] Khademi A, Renani NG, Mofarrahhi M, Jeddi AR, Yusof NM. The best location for speed bump installation using experimental design methodology. Promet - Traffic \& Transportation. 2013;25:6-565-574.

[31] Mee R. A comprehensive guide to factorial two-level experimentation. Springer Science \& Business Media. 2009.

[32] Zhu Y, Antao DS, Chu KH, Chen S, Hendricks TJ, Zhang T, Wang EN. Surface structure enhanced microchannel flow boiling. Journal of Heat Transfer. 2016;138:091501.

[33] Micheli L, Reddy KS, Mallick TK. Plate micro-fins in natural convection: an opportunity for passive concentrating photovoltaic cooling. Energy Procedia. 2015;82:301-308.

[34] Pal VK, Choudhury SK. Fabrication and analysis of micro-pillars by abrasive water jet machining. Procedia Materials Science. 2014;6:61-71.

[35] Kapoor J, Sigh S, Khamba JS. High-performance wire electrodes for wire electricaldischarge machining - a review. Proceedings of the Institution of Mechanical Engineers, Part B: Journal of Engineering Manufacture. 2012;226:11-1757-1773.

[36] Bhandare AS, Dabade UA. Experimental investigations during dry EDM of Inconel718. IOP Conference Series: Materials Science and Engineering. 2016;114:012035.

[37] Zhou W, Apkarian R, Wang ZL, Joy D. Fundamentals of scanning electron microscopy (SEM). In Scanning microscopy for nanotechnology. Springer NewYork, 2006;1-40

[38] Ndaliman MB, Al-Hazza MHF, Khan AA, Ali MY. (September, 2014). Modeling surface roughness of Ti6Al4V alloy subjected to EDM with $\mathrm{Cu}-\mathrm{TaC}$ electrode using response surface methodology. retrieved from https://www.researchgate.net/publication/321070863_Modeling_surface_roughness_o f_Ti6Al4V_alloy_subjected_to_EDM_with_Cu-

TaC_electrode_using_response_surface_methodology dated on 12 February 2017.

[39] Khan MAR, Rahman MM, Kadirgama K. Electrode wear rate of graphite electrodes during electrical discharge machining processes on titanium alloy Ti-5Al-2.5Sn. International Journal of Automotive and Mechanical Engineering. 2014;9:1782-1792.

[40] Conde A, Arriandiaga A, Sanchez JA, Portillo E, Plaza S, Canabes I. High-accuracy wire electrical discharge machining using artificial networks and optimization techniques. Robotics and Computer-Integrated Manufacturing. 2018;49:24-38

[41] Habib, S. \& Okada, A. (2016). Experimental investigation on wire vibration during fine wire electrical discharge machining process. International Journal of Advanced Manufacturing Technology, 84 (9-12), 2265-2276.

[42] Maradia U, Wegener K. EDM Modelling and Simulation. In Electrical Discharge Machining (EDM) Types, Technologies and Application. Jahan MP, Ed. New York: Nova Science Publishers, Inc., 2015;67-121.

[43] Macedo FTB, Wiessner M, Hollenstein C, Esteves PMB, Wegener K. Fundamental investigation of dry electrical discharge machining (DEDM) by optical emission spectroscopy and its numerical interpretation. International Journal of Advanced Manufacturing Technology. 2016;1-13. 